\title{
MANAGEMENT OF THE COVID-19 HEALTH CRISIS:A SURVEY IN SWISS HOSPITAL PHARMACIES
}

Laurence Schumacher, PharmD ${ }^{1,2^{*}}$; Yassine Dhif, PharmD ${ }^{3 *}$; Pascal Bonnabry, PharmD, PhD ${ }^{1,3}$; Nicolas Widmer, PharmD, $\mathrm{PhD}^{1,2}$

1 Specialized Centre for Emergency and Disaster Pharmacy, Institute of Pharmaceutical Sciences of Western Switzerland, School of Pharmaceutical Sciences, University of Geneva, Geneva, Switzerland

2 Pharmacy of Eastern Vaud Hospitals, Rennaz, Switzerland

3 Pharmacy of Geneva University Hospitals, Geneva, Switzerland

* These two authors contributed equally

\section{Address for correspondence:}

PD Dr Nicolas Widmer

Institute of Pharmaceutical Sciences of Western Switzerland

School of pharmaceutical sciences

University of Geneva, CMU

1 , rue Michel-Servet

1211 Genève 4

Switzerland

Email: Nicolas.Widmer@unige.ch

Phone: +41587734814

\section{Running title:}

Swiss hospital pharmacies COVID-19 management

\section{Sources of support that require acknowledgment:}

This study was funded by the Swiss Federal Department of Defence, Civil Protection and Sport, through the Centre of Competence for Military and Disaster Medicine. The survey was reviewed by the steering committee of the Swiss Society of Public Health Administration and Hospital Pharmacists, especially PD Dr Johnny Benney, past president.

\section{Conflicts of interest/competing interests:}

The authors have declared no potential conflicts of interest. 
medRxiv preprint doi: https://doi.org/10.1101/2020.12.08.20237339; this version posted December 11, 2020. The copyright holder for this preprint (which was not certified by peer review) is the author/funder, who has granted medRxiv a license to display the preprint in perpetuity. All rights reserved. No reuse allowed without permission.

\section{$\underline{\text { ABSTRACT }}$}

Objective: This survey aims at reviewing the actions undertaken by Switzerland's hospital pharmacies during the first wave of COVID-19 pandemic.

Methods: A questionnaire covering topics related to the management of the COVID-19 crisis was sent to 65 heads of swiss hospital pharmacy.

Results: $59 \%$ of pharmacies reported changes in the role of their staff. $41 \%$ of pharmacies had existing standard operating procedures or pandemic plans. 51\% created new drug lists for: COVID19-specific treatments (83\% of pharmacies), sedatives $(81 \%)$, anaesthetics $(77 \%)$ and antibiotics (73\%). Drug availability in COVID-19 wards was managed by increasing existing stocks (54\% of pharmacies) and creating extra storage space (51\%). Two drugs generated the most concern about shortages: propofol (49\% of pharmacies) and midazolam (44\%). Remdesivir stocks even ran out in $26 \%$ of pharmacies. $77 \%$ of pharmacies experienced problems procuring hand sanitiser solutions and $53 \%$ manufactured these themselves. Specific new documents were drafted to respond to medical needs with regards to drug administration (29\% of pharmacies), drug preparation (29\%) and treatment choices (24\%). $47 \%$ of pharmacies implemented internal specific hygiene measures and $28 \%$ introduced team debriefings.

Conclusions: Swiss hospital pharmacies encountered many challenges related to the COVID-19 crisis and had to find solutions quickly and effectively.

\section{KEYWORDS}

Disasters; Response; COVID-19; Pandemics; Hospital Pharmacy, Service

\section{ABBREVIATION LIST}

COVID-19: Coronavirus disease 2019

EpidA: Swiss Federal Act on Epidemics

F: French-speaking region of Switzerland

FC: Swiss Federal Council

G: German-speaking region of Switzerland

GSASA: Swiss Society of Public Health Administration and Hospital Pharmacists

HP: Hospital pharmacies

HR: human resource

I: Italian-speaking region of Switzerland

ICU: Intensive Care Unit

MERS-CoV: Middle East respiratory syndrome coronavirus

PPE: Personal Protective Equipment

PPP: Pandemic Preparedness Plan

R: Romansh-speaking region of Switzerland

SARS-CoV-1: Severe acute respiratory syndrome coronavirus 1

SARS-CoV-2: Severe acute respiratory syndrome coronavirus 2

SOP: Standard operating procedures

Swissmedic: Swiss Agency for Therapeutic Products 
medRxiv preprint doi: https://doi.org/10.1101/2020.12.08.20237339; this version posted December 11, 2020. The copyright holder for this preprint (which was not certified by peer review) is the author/funder, who has granted medRxiv a license to display the preprint in perpetuity.

All rights reserved. No reuse allowed without permission.

\section{WHO: World Health Organisation}


medRxiv preprint doi: https://doi.org/10.1101/2020.12.08.20237339; this version posted December 11, 2020. The copyright holder for this preprint (which was not certified by peer review) is the author/funder, who has granted medRxiv a license to display the preprint in perpetuity. All rights reserved. No reuse allowed without permission.

\section{INTRODUCTION}

The year 2020 is marked by the Coronavirus Disease 2019 (COVID-19) pandemic, which will certainly go down in history. Common human coronaviruses (229E, OC43, NL63, HKU1) appear very frequently and cause relatively mild to moderate upper-respiratory tract illness, especially during winter. They contribute to between $15 \%$ and $30 \%$ of cases of common colds in human adults (1). Other coronaviruses include the highly pathogenic severe acute respiratory syndrome coronavirus (SARS-CoV-1), discovered in 2003, and the Middle East respiratory syndrome coronavirus (MERS-CoV), which appeared in 2012. Both are associated with high mortality rates, of around $10 \%$ and $35 \%$, respectively (2).

In December 2019, the city of Wuhan, capital of Hubei Province in China, with a population of more than 11 million people, reported the first cases of pneumonia due to a new, previously unknown coronavirus (3). In February 2020, the World Health Organisation (WHO) officially named this new virus SARS-CoV-2 and the disease it caused COVID-19, short for Coronavirus Disease 2019. Human-to-human transmission has been confirmed (4). The number of cases in China increased steadily until the second half of February. The first case of COVID-19 in Switzerland was confirmed on 25 February 2020 in the canton of Ticino. On 28 February, in accordance with the Federal Act on Epidemics (EpidA), the Swiss Federal Council (FC) declared a "special situation" by presenting the COVID-19 Ordinance, and it prohibited gatherings of more than 1,000 people. At the beginning of March 2020, the number of cases detected became increasingly important in Europe, mainly in Italy, where the European outbreak started (5). On 5 March, the first coronavirus-related death in Switzerland was confirmed by the authorities in the canton of Vaud. On 11 March 2020, the WHO declared the COVID-19 epidemic to be a pandemic. On 12 March, Switzerland had the third highest prevalence of COVID-19 of any European country affected by the coronavirus. On 13 March, by means of COVID-19 Ordinance 2, the FC announced a tightening of measures throughout the country, including a ban on gatherings of more than 100 people, the closure of all schools and universities and the introduction of border controls. Simultaneously, many cantons announced tighter restrictions. On 16 March, the FC declared an "extraordinary situation" (Art. 7 EpidA) and updated Ordinance 2 with new measures: the closure of non-essential businesses (including restaurants and leisure facilities) and partial border closures (6). Progressively, it also mobilised several conscript formations of the Swiss Armed Forces to assist the cantons with healthcare, logistics and security (7). On June 19, 2020, in view of a general decline in the number of infections, the FC was able to lift the state of "extraordinary situation", while maintaining a state of "special situation".

The healthcare system did not reach saturation despite Switzerland being one of the most highly affected countries in the world, with prevalence increasing from 7.2 to 357 cases per 100,000 inhabitants between 9 March and 19 May 2020 (8). The services of hospital pharmacies (HPs) were in high demand during this first wave of the pandemic because of their critical responsibility for the supply of therapeutic products. As of November 2020, Switzerland is facing an important second wave of the COVID-19 pandemic.

The present study's objectives were to obtain an overview of the actions undertaken by HPs across Switzerland as they responded to the challenges encountered during the first wave of the COVID-19 pandemic and to provide information to improve pharmaceutical management in future health crises. 


\section{METHOD}

A closed survey using a web-based open questionnaire designed on the SurveyMonkey ${ }^{\circledR}$ platform (SurveyMonkey, San Mateo, CA, USA; http://www.surveymonkey.com) was conducted. The related research protocol, which did not imply patient data collection, has been presented to the Cantonal Research Ethics Committee Geneva, which waived an ethical oversight.

Questions were organised into eleven clusters: general information about the respondent, the HP and the hospital, management of this crisis, human resources management, drugs used primarily in intensive care units (ICUs), drugs used specifically for treating SARS-CoV-2, drug management in COVID-19 care units (including ICUs), hygiene, support for medical and care teams, care management for patients recovering from COVID-19, other problems encountered, and future perspectives. Altogether, it consisted of 67 questions and used adaptative design to create a custom pathway through the survey depending on the respondent's answers. Therefore, not all participants needed to answer every question. Most of the questions were multiple-choice and allowed multiple answers. The questions were reviewed by the steering committee of the Swiss Society of Public Health Administration and Hospital Pharmacists (GSASA) and the survey was tested on the web platform by two head pharmacists before fielding.

Data were collected between 19 May and 19 June 2020 via an anonymous questionnaire sent out by individually by email to all the country's head hospital pharmacists affiliated to the GSASA, to avoid duplicate entries. Email reminders were sent out at two, three and four weeks after the first mailing. Provision of the survey results was offered to participants as incentive.

Data were analysed using standard descriptive statistics. Means and proportions were calculated using the total number of participants responding to a given question. Responses left blank were coded as missing data and handled using a listwise deletion method.

\section{$\underline{\text { RESULTS }}$}

\section{GENERAL INFORMATION}

Answers of 43 participants were obtained out of 65 questionnaires sent, which represented a participation rate of $66 \%$. Switzerland's population is spread across four linguistic regions: German-speaking (G), French-speaking (F), Italian-speaking (I) and Romansh-speaking (R). Most of our study participants worked in German-speaking regions $(\mathrm{n}=33,77 \%)$ and only one participant (2\%) worked in each of the Romansh-speaking and Italian-speaking regions. The remaining participants worked in French-speaking regions $(n=8,19 \%)$. To simplify the analysis, French- and Italian-speaking participants were grouped together (F/I), and so were German- and Romanshspeaking head hospital pharmacists (G/R). Participants took 30-40 minutes to complete the survey.

Most head pharmacists worked in HPs with less than 50 employees $(n=35,81 \%)$ and only three HPs (7\%) had more than 100 employees. In their standard configurations, most of the hospitals ( $\mathrm{n}=26$, $60 \%$ ) had fewer than 300 beds, 15 (35\%) had 300 to 1000 beds, and $2(5 \%)$ had more than 1000 beds. Regarding their ICU facilities, most of the hospitals $(n=22,51 \%)$ had fewer than 10 beds, 21 
(49\%) had 10 to 50 beds, and none of the participating hospitals had more than 50 ICU beds in their standard configuration. Pharmacy staff themselves were only infected in $26 \%$ of HPs $(n=10)(88 \%$ F/I, $10 \% \mathrm{G} / \mathrm{R}$ ), but none of these HPs experienced more than $5 \%$ prevalence among their staff. The other $74 \%$ of HPs $(n=33)$ had no infected staff.

\section{MANAGEMENT OF THE CRISIS}

During the first wave of the COVID-19 outbreak, the number of ICU beds available was increased above standard configurations. The percentage of hospitals with fewer than ten ICU beds available daily declined by $14 \%$ (from $51 \%$ to $37 \%$, or $n=22$ to $n=16$ ). In contrast, the percentage of hospitals with from 10 to 50 ICU beds available daily grew by $15 \%$ (from $49 \%$ to $64 \%$, or $n=21$ to $n=23$ ). In addition, $9 \%$ of hospitals $(n=4)$ opened supplementary ICU wards to go beyond 50 ICU beds dedicated to COVID-19 patients.

Regarding disaster management plans, $41 \%(\mathrm{n}=17)$ of HPs had previously prepared internal standard operating procedures (SOPs), whether general disaster SOPs $(n=7,17 \%)$ or specific pandemic plans $(\mathrm{n}=10,24 \%) ; 18 \%(\mathrm{n}=7)$ of HPs had a business continuity plan prior to the pandemic $(38 \% \mathrm{~F} / \mathrm{I}, 13 \% \mathrm{G} / \mathrm{R})$; and an equal number of HPs $(\mathrm{n}=7,18 \%)$ created a plan especially to manage the pandemic. Of those HPs which had a pandemic/disaster management plan prior to the COVID-19 crisis, 56\% ( $\mathrm{n}=9)$ did however not have a business continuity plan. This percentage rose to $70 \%(\mathrm{n}=16)$ among HPs which did not have a pandemic/crisis management plan prior to the COVID-19 crisis. The details of the business continuity plans are listed in Table 1.

\section{Table 1. Business continuity plan}

\begin{tabular}{|c|c|c|c|}
\hline & $\begin{array}{c}\text { Total } \\
\text { n }(\%) *\end{array}$ & $\begin{array}{l}\text { German } \\
\text { n }(\%) \neq\end{array}$ & $\begin{array}{l}\text { French } \\
\text { n }(\%) \S\end{array}$ \\
\hline $\begin{array}{l}\text { All key functions and tasks were listed, with the names of the persons } \\
\text { responsible }\end{array}$ & $9(22)$ & $4(12)$ & $5(63)$ \\
\hline $\begin{array}{l}\text { Tasks which could, in great part, be carried out at home (teleworking) were } \\
\text { identified }\end{array}$ & $9(22)$ & $4(12)$ & $5(63)$ \\
\hline $\begin{array}{l}\text { Tasks which could be put on hold and whose usual staff could be moved to } \\
\text { other roles were identified }\end{array}$ & $8(20)$ & $4(12)$ & $4(50)$ \\
\hline All key functions and tasks had pre-identified replacements or deputies & $7(17)$ & $3(9)$ & $4(50)$ \\
\hline $\begin{array}{l}\text { Job functions at risk of severe contamination were identified (direct contact } \\
\text { with other persons or clients, etc.) }\end{array}$ & $7(17)$ & $3(9)$ & $4(50)$ \\
\hline $\begin{array}{l}\text { Tasks which must imperatively be carried out within the pharmacy itself were } \\
\text { identified }\end{array}$ & $6(15)$ & $4(12)$ & $2(25)$ \\
\hline Some staff were trained for new roles and tasks before any staff shortages & $5(12)$ & $2(6)$ & $3(38)$ \\
\hline $\begin{array}{l}\text { Some staff were trained for new roles and tasks because of absences or illness } \\
\text { among the usual persons responsible }\end{array}$ & $2(5)$ & $0(0)$ & $2(25)$ \\
\hline Key posts were assigned dual leadership & $2(5)$ & $1(3)$ & $1(13)$ \\
\hline $\begin{array}{l}\text { Tasks which could be carried out by external companies or contractors were } \\
\text { identified }\end{array}$ & $2(5)$ & $1(3)$ & $1(13)$ \\
\hline
\end{tabular}

* Among 41 answers. $\ddagger$ Among 33 answers (German/Romansh) § Among 8 answers (French/Italian)

Most HPs ( $n=41,95 \%)$ created a steering committee to manage the crisis. This was often composed of the head pharmacist ( $n=25,61 \%)$, a member of the pharmaceutical logistics unit $(n=14,34 \%)$, a representative from outside the pharmacy $(n=13,32 \%)$, a representative of the hospital's general crisis management team $(n=11,27 \%)$, a representative from the cantonal authorities $(n=9,22 \%)$ and a member of the clinical pharmacy unit or the pharmaceutical assistance unit $(n=8,20 \%)$. Among 
HPs with a disaster management plan, $52 \%(\mathrm{n}=9)$ created paper or electronic dashboards or another management tool (i.e. an Excel $^{\circledR}$ file) especially for the COVID-19 crisis, but $24 \%(n=4)$ had no dashboards at all. The remaining $24 \%(\mathrm{n}=4)$ used previously prepared dashboards. Of the HPs without prior SOPs, $61 \%(\mathrm{n}=14)$ created dashboards specifically to manage the crisis. The panels of those dashboards are listed in Table 2. It is worth noting that only two HPs (5\%) had a panel of risks management.

\section{Table 2. Information present on dashboard panels for the management of the COVID-19 crisis}

\begin{tabular}{|c|c|c|c|}
\hline & $\begin{array}{c}\text { Total } \\
\text { n }(\%)^{*}\end{array}$ & $\begin{array}{c}\text { German } \\
\text { n }(\%) \neq\end{array}$ & $\begin{array}{l}\text { French } \\
\text { n }(\%) \S\end{array}$ \\
\hline Overview of essential stock items requiring monitoring & $21(49)$ & $15(44)$ & $6(67)$ \\
\hline Summary report of the hospital situation & $16(37)$ & $12(35)$ & $4(44)$ \\
\hline Situation at the pharmacy & $16(37)$ & $11(32)$ & $5(56)$ \\
\hline Situation overview & $13(30)$ & $9(26)$ & $4(44)$ \\
\hline General problems affecting the pharmacy & $10(23)$ & $7(21)$ & $3(33)$ \\
\hline Number of pharmacy employees & $8(19)$ & $5(15)$ & $3(33)$ \\
\hline Forward/provisional planning & $8(19)$ & $4(12)$ & $4(44)$ \\
\hline Problems faced by different units in the pharmacy & $7(16)$ & $4(12)$ & $3(33)$ \\
\hline Important contacts & $7(16)$ & $5(15)$ & $2(22)$ \\
\hline List of key functions & $6(14)$ & $6(18)$ & $0(0)$ \\
\hline Journal of events & $5(12)$ & $2(6)$ & $3(33)$ \\
\hline Emergency measures & $4(9)$ & $2(6)$ & $2(22)$ \\
\hline Problem assessment (synthesis of problems encountered) & $2(5)$ & $0(0)$ & $2(22)$ \\
\hline Pending issues & $2(5)$ & $0(0)$ & $2(22)$ \\
\hline Risks management & $2(5)$ & $1(3)$ & $1(11)$ \\
\hline Task completion status & $2(5)$ & $1(3)$ & $1(11)$ \\
\hline Schedule of the next situation updates & $2(5)$ & $0(0)$ & $2(22)$ \\
\hline
\end{tabular}

* Among 43 answers. $\ddagger$ Among 34 answers (German/Romansh) § Among 9 answers (French/Italian)

Thirty-nine HPs evaluated the usefulness of the support provided by various public authorities and affiliated agencies ( 8 in total) in the management of the health crisis. The GSASA was considered the most useful agency (mean score 4.2/5), followed by the cantonal pharmacist (mean score 3.6/5), and the Swiss Agency for Therapeutic Products (Swissmedic) was considered the least useful (1.9/5). For the support provided in the management of shortages of drugs used mainly in ICUs and for the treatment of SARS-CoV-2, the GSASA was considered the most useful agency (mean scores $3.9 / 5$ and 3.5/5, respectively), followed by the cantonal pharmacist (mean scores 3.5/5 and 3.1/5, respectively), and, again, Swissmedic was considered the least useful (1.5/5 and 1.2/5, respectively).

\section{HUMAN RESOURCES MANAGEMENT}

Hospital guidelines were the main source of human resource (HR) management advice during the COVID-19 outbreak ( $n=30,70 \%)$. The main changes in HR management carried out are summarised in Table 3. 59\% of HPs reported that some of their staff had to change roles: from $21 \%$ of HPs changing $<10 \%$ of roles to $3 \%(n=1)$ of HPs changing $>50 \%$ of roles. Role changes occurred in the following fields: disinfectants manufacturing (collecting bottles, production, and filling done by pharmacists and volunteers), administrative work for ICUs (done by pharmacy technicians), pharmacists also acted as pharmacy technicians on wards and logisticians in drug distribution, with $10 \%(\mathrm{n}=4)$ of HPs reassigning pharmacists to these tasks. Only $1 \mathrm{HP}(2 \%)$ had to hire extra staff for these tasks. In some HPs $(n=12,28 \%)$, to preserve the health of the employees, 
staff were obliged to use up all their leave and overtime hours during the crisis, so they can rest. To the opposite, some hospitals $(n=8,19 \%)$ cancelled planned holidays, leave and days off for a certain period. In about half of the French-speaking HPs, a support was provided by personnel of the civil protection $(\mathrm{n}=5,56 \% \mathrm{~F} / \mathrm{I})$ or civilian service $(\mathrm{n}=1,11 \% \mathrm{~F} / \mathrm{I})$, but no swiss HPs obtained or asked support from the military medical troops mobilised.

Table 3. Human resources management

\begin{tabular}{|c|c|c|c|}
\hline & $\begin{array}{l}\text { Total } \\
\text { n }(\%) *\end{array}$ & $\begin{array}{c}\text { German } \\
\text { n }(\%) \ddagger\end{array}$ & $\begin{array}{l}\text { French } \\
\text { n }(\%) \S\end{array}$ \\
\hline New activities had to be created to respond to the specific needs of the crisis & $29(67)$ & $22(65)$ & $7(78)$ \\
\hline Activities had to be reorganised & $27(63)$ & $21(62)$ & $6(67)$ \\
\hline Staff with functions that permitted it were asked to work from home & $25(58)$ & $19(56)$ & $6(67)$ \\
\hline $\begin{array}{l}\text { Only essential activities were maintained (non-urgent activities were shut } \\
\text { down) }\end{array}$ & $24(56)$ & $19(56)$ & $5(56)$ \\
\hline $\begin{array}{l}\text { Staff at risk were moved to safer environments (either home or restricted to } \\
\text { low-risk activities) }\end{array}$ & $20(47)$ & $12(35)$ & $8(89)$ \\
\hline Normal activities were maintained during the crisis & $20(47)$ & $16(47)$ & $4(44)$ \\
\hline $\begin{array}{l}\text { Pharmacy telephone numbers were rerouted, and access to the pharmacy } \\
\text { computer network was provided to pharmacists working from home }\end{array}$ & $11(26)$ & $6(18)$ & $5(56)$ \\
\hline Extra staff were recruited from among volunteers & $11(26)$ & $8(24)$ & $3(33)$ \\
\hline Others** & $8(19)$ & $8(24)$ & $0(0)$ \\
\hline A dedicated pandemic response team was set up & $8(19)$ & $4(12)$ & $4(44)$ \\
\hline Extra staff were recruited from among civil protection units & $7(16)$ & $2(6)$ & $5(56)$ \\
\hline Substitute or replacement staff were organised (especially in key functions) & $7(16)$ & $5(15)$ & $2(22)$ \\
\hline Shift teams were kept together to avoid any mixing of staff & $5(12)$ & $4(12)$ & $1(11)$ \\
\hline Sick leave was compensated & $5(12)$ & $5(15)$ & $0(0)$ \\
\hline Extra staff were recruited from among civilian service personnel & $4(9)$ & $3(9)$ & $1(11)$ \\
\hline Extra staff were recruited from among former employees & $3(7)$ & $3(9)$ & $0(0)$ \\
\hline Extra staff were recruited from among retired HP staff & $2(5)$ & $1(3)$ & $1(11)$ \\
\hline No changes in practice & $2(5)$ & $2(6)$ & $0(0)$ \\
\hline A business continuity plan was developed at the start of the crisis & $1(2)$ & $0(0)$ & $1(11)$ \\
\hline Extra staff were recruited from the Swiss Armed Forces & $0(0)$ & $0(0)$ & $0(0)$ \\
\hline $\begin{array}{l}\text { Free telephone numbers were set up for maintaining contact with staff, } \\
\text { clients and suppliers }\end{array}$ & $0(0)$ & $0(0)$ & $0(0)$ \\
\hline
\end{tabular}

* Among 43 answers $\ddagger$ Among 34 answers (German/Romansh) §Among 9 answers (French/Italian)

**e.g. extra staff from other hospitals, free parking provided by local authorities to avoid public transport use, staff presence minimised in order to minimise virus transmission risk, paid leave for pharmacy technicians because of closed inpatients units.

Psychological support was organised to support HP teams. Many HPs, for example, encouraged solidarity between staff members $(n=25,58 \%)$. Teams were given regular situation updates and, in most cases, their consequences were explained to stop rumours $(n=19,44 \%)$. Team briefing and debriefings were introduced $(n=12,28 \%)$ to establish a climate of trust. Many HP hierarchies calmed and reassured their staff $(n=17,40 \%)$. Dedicated telephone helplines were also set up ( $n=11$, $26 \%$ ) to maintain contact with staff, clients (namely wards, other hospital pharmacies or a public pharmacy) and suppliers. More flexible work scheduling was implemented ( $n=7,16 \%)$, yet one in five HPs introduced no new measures $(\mathrm{n}=9,21 \%)$. Moreover, almost half of the HPs implemented specific internal hygiene measures $(n=20,47 \%)$.

\section{DRUGS MANAGEMENT}

To limit risks of any shortages, 56\% of HPs $(n=23)$ had anticipated reserve supplies (100\% F/I regions, $45 \% \mathrm{G} / \mathrm{R}$ regions). A list of drugs used for treating COVID-19 patients and their supply problems is compiled in Figure 1. 34\% of HPs $(n=14)$ imported drugs from the European Union (63\% F/I regions, $27 \% \mathrm{G} / \mathrm{R}$ regions), but only $7 \%(\mathrm{n}=3)(25 \% \mathrm{~F} / \mathrm{I}$ regions, $3 \% \mathrm{G} / \mathrm{R}$ regions) had to 
medRxiv preprint doi: https://doi.org/10.1101/2020.12.08.20237339; this version posted December 11, 2020. The copyright holder for this preprint (which was not certified by peer review) is the author/funder, who has granted medRxiv a license to display the preprint in perpetuity. All rights reserved. No reuse allowed without permission.

import from a country outside those usually authorised. $10 \%(\mathrm{n}=4)$ of HPs asked a statistician to provide stock forecasts ( $13 \% \mathrm{~F} / \mathrm{I}$ regions, $9 \% \mathrm{G} / \mathrm{R}$ regions). Only $22 \%$ of HPs $(\mathrm{n}=9)$ managed never to run out of drug stocks at all (13\% F/I regions, $24 \% \mathrm{G} / \mathrm{R}$ regions). 
Figure 1: Stocks of drugs for the treatment of patients with COVID-19 that ran out and generated concern.

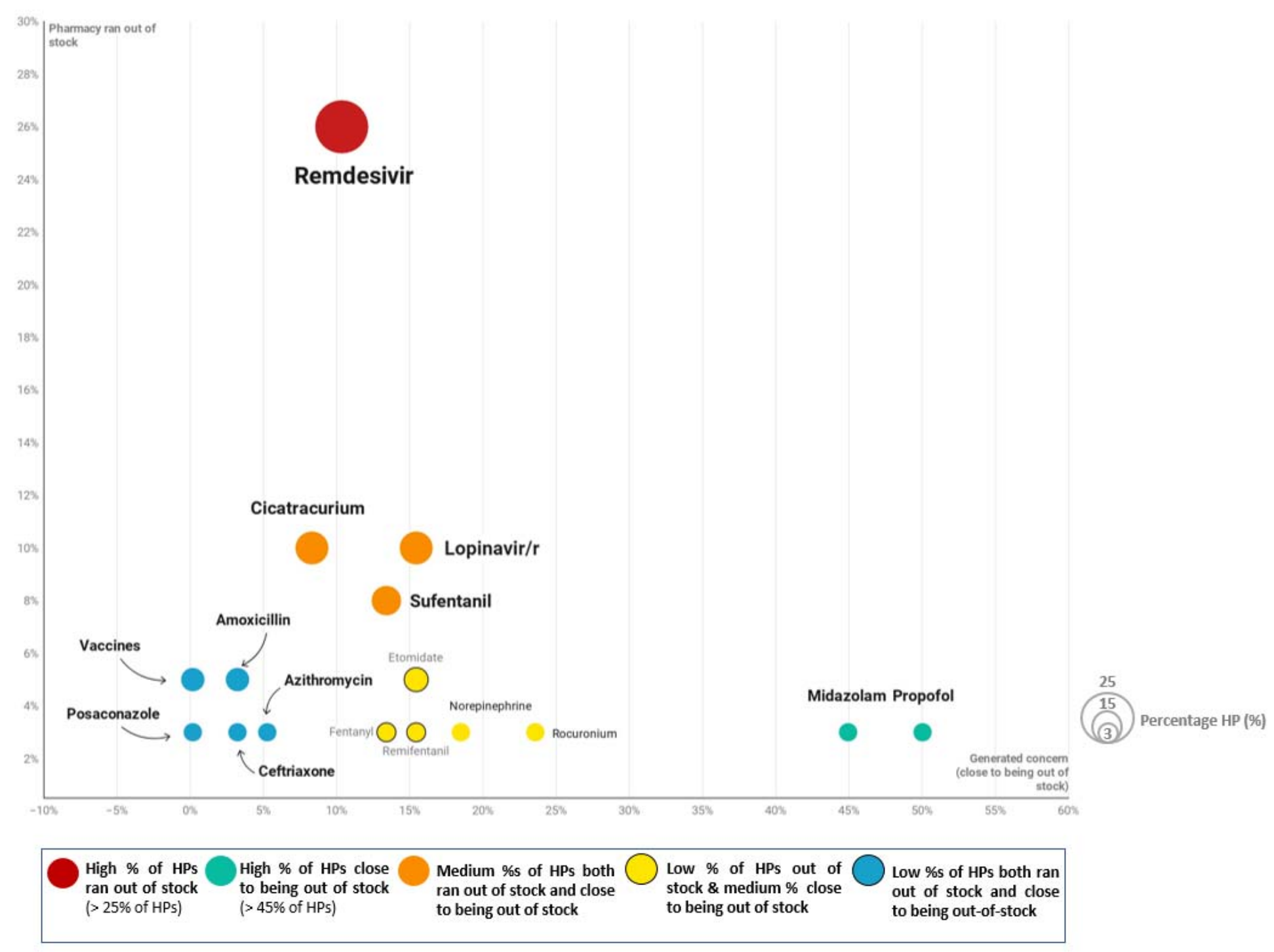


$36 \%(\mathrm{n}=14)$ of HPs were involved in either the Solidarity $(\mathrm{n}=9,64 \%)$ or Discovery studies $(\mathrm{n}=1,7 \%)$, as well as other clinical trials, such as the Early Access Program for remdesivir $(\mathrm{n}=9,64 \%)$. Among the HPs involved in these studies, $71 \%(\mathrm{n}=10)$ had their hospital participating in the study/project and thus had to provide the drugs; $50 \%(n=7)$ worked on them in partnership with medical and care staff, and $43 \%(n=6)$ had a dedicated pharmacist consulting for the study/project.

Drug stocks on wards treating COVID-19 patients were sometimes managed by assigning dedicated pharmacy technicians $(\mathrm{n}=12,29 \%)$. HPs reassigned tasks related to drug stock management in wards to other professionals $(27 \%, \mathrm{n}=11)$, such as nurses. Some pharmacy technicians were reassigned by splitting their time between COVID-19 care units and their usual tasks $(n=8,20 \%)$. $76 \%$ of HPs $(n=31)$ managed the risk of shortages by strictly monitoring the drugs dedicated to COVID-19 patients (63\% F/I regions, $79 \% \mathrm{G} / \mathrm{R}$ regions).

$63 \%$ of HPs ( $\mathrm{n}=26 ; 75 \% \mathrm{~F} / \mathrm{I}$ regions, $61 \% \mathrm{G} / \mathrm{R}$ regions) found alternative drugs and proposed these instead to medical staff or their healthcare institution. Alternatives were proposed to guarantee the continuity of care and save the stocks. For example, in some HPs, an anaesthetics savings strategy was put in place to preserve the stocks of midazolam and propofol by indicating which drug must be used first and for how long. $27 \%$ of HPs $(n=11)$ had to prepare alternative protocols in partnership with medical or care staff in case these potential shortages occurred (50\% F/I regions, $21 \% \mathrm{G} / \mathrm{R}$ regions). However, medical staff imposed their choices of compounds and/or their corresponding protocols on $15 \%$ of HPs $(n=6)$.

Generally, $51 \%$ of HPs $(n=20)$ created specific drug lists for care units treating COVID-19 patients (63\% F/I regions, 48\% G/R regions). Types of drugs contained in these lists are summarised in Table 4.

\section{Table 4. Drugs used for treating COVID-19 patients}

\begin{tabular}{|c|c|c|}
\hline Therapeutic class & $\mathbf{n}(\%)$ & Drugs \\
\hline $\begin{array}{l}\text { COVID-19 } \\
\text { treatments }\end{array}$ & $22(83)$ & $\begin{array}{l}\left.\text { Lopinavir/ritonavir (Kaltera }{ }^{\circledR}\right) \text { and equivalents, hydroxychloroquine } \\
\left(\text { Plaquenil }^{\circledR}\right) \text { and equivalents, remdesivir }\left(\text { Veklury }^{\circledR}\right) \text {, tocilizumab (Actemra }{ }^{\circledR} \text { ) }\end{array}$ \\
\hline Sedatives & $21(81)$ & Dexmedetomidine, lorazepam, midazolam \\
\hline Anaesthetics & $20(77)$ & $\begin{array}{l}\text { Etomidate, fentanyl, ketamine, propofol, remifentanil, sufentanil, } \\
\text { suxamethonium }\end{array}$ \\
\hline Antibiotics & $19(73)$ & $\begin{array}{l}\text { Amikacin, amoxicillin, azithromycin, ceftriaxone, cefuroxime, } \\
\text { imipenem/cilastatin, meropenem, piperacillin/tazobactam, posaconazole }\end{array}$ \\
\hline Curares & $15(58)$ & Atracurium, cisatracurium, rocuronium \\
\hline Electrolytes & $11(42)$ & ND \\
\hline Perfusions & $10(38)$ & Heparin, insulin \\
\hline Laxatives & $4(15)$ & ND \\
\hline Others & $3(12)$ & Anticoagulation drugs, G-CSF and nutritional supplements \\
\hline
\end{tabular}

ND: No data

Drug production units in $24 \%$ of HPs $(\mathrm{n}=10)$ reconditioned drugs $(38 \% \mathrm{~F} / \mathrm{I}$ regions, $21 \% \mathrm{G} / \mathrm{R}$ regions). $10 \%$ of HPs $(n=4)$ had to produce drugs $(25 \% \mathrm{~F} / \mathrm{I}$ regions, $6 \% \mathrm{G} / \mathrm{R}$ regions). The main drugs manufactured by HPs were hydromorphone, midazolam, morphine, ketamine, fentanyl (all parenteral forms) and hydroxychloroquine (HCQ) suspension. 


\section{SUPPORT FOR MEDICAL AND CARE TEAMS}

$49 \%$ of HPs $(n=19)$ worked together with other clinical teams in their hospital to provide appropriate treatment management protocols for COVID-19 patients arriving at the ICU: $63 \%$ $(n=5)$ in $F / I$ regions but only $45 \%(n=14)$ in $\mathrm{G} / \mathrm{R}$ regions. Only $13 \%(\mathrm{n}=5)$ had no specific protocol available, and $13 \%(n=5)$ received protocols from their hospital without having been consulted. Whatever, HPs played a key role in many aspects of the COVID-19 pandemic by providing clinical and logistical support to medical and care teams. Pharmacists were present to support ICU care (20\% of HPs, $n=8)$ and medical staff ( $24 \%$ of HPs, $n=10)$. Specific documents were drawn up to respond to medical needs regarding drug administration (29\% of HPs, $n=12)$, drug preparation ( $29 \%$ of HPs, $n=12)$ and treatment choices ( $24 \%$ of HPs, $n=10)$. Detailed support activities for medical and care teams are listed in Table 5.

\section{Table 5. Support activities implemented by hospital pharmacies for medical and care units}

\begin{tabular}{|c|c|c|c|}
\hline & $\begin{array}{c}\text { Total } \\
\mathbf{n} \\
(\%)^{*}\end{array}$ & $\begin{array}{l}\text { German } \\
\text { n }(\%) \ddagger\end{array}$ & $\begin{array}{l}\text { French } \\
\text { n }(\%) \S\end{array}$ \\
\hline Questions were dealt with by the usual pharmaceutical hotline & $26(68)$ & $21(64)$ & $7(88)$ \\
\hline $\begin{array}{l}\text { Specific documents were drawn up to respond to medical and care staff's needs } \\
\text { regarding drug administration }\end{array}$ & $12(29)$ & $8(24)$ & $4(50)$ \\
\hline $\begin{array}{l}\text { Specific documents were drawn up to respond to medical and care staff's needs } \\
\text { regarding drug preparation }\end{array}$ & $12(29)$ & $9(27)$ & $3(38)$ \\
\hline A pharmacist was present in the ICU to support medical staff & $10(24)$ & $4(12)$ & $6(75)$ \\
\hline $\begin{array}{l}\text { Specific documents were drawn up to respond to medical and care staff's needs } \\
\text { regarding treatment choices }\end{array}$ & $10(24)$ & $6(18)$ & $4(50)$ \\
\hline A pharmacy technician was present in the ICU to help resupply wards with drugs & $9(22)$ & $6(18)$ & $3(38)$ \\
\hline A pharmacist was present in the ICU to support care staff & $8(20)$ & $3(9)$ & $5(63)$ \\
\hline $\begin{array}{l}\text { A pharmacy technician was present in other care units treating COVID-19 patients } \\
\text { to help resupply wards with drugs }\end{array}$ & $8(20)$ & $5(15)$ & $3(38)$ \\
\hline $\begin{array}{l}\text { A pharmacist was present in other care units treating COVID-19 patients to support } \\
\text { medical staff }\end{array}$ & $7(17)$ & $3(9)$ & $4(50)$ \\
\hline $\begin{array}{l}\text { A pharmacist was present in other care units treating COVID-19 patients to support } \\
\text { nurses }\end{array}$ & $4(10)$ & $1(3)$ & $3(38)$ \\
\hline $\begin{array}{l}\text { A pharmacy technician was present in other care units treating COVID-19 patients } \\
\text { to help nurses withdraw drugs from their care unit's drug stocks }\end{array}$ & $2(5)$ & $1(3)$ & $1(13)$ \\
\hline $\begin{array}{l}\text { A dedicated pharmacy hotline was set up to answer care staff's questions linked to } \\
\text { treating COVID-19 }\end{array}$ & $2(5)$ & $0(0)$ & $2(25))$ \\
\hline $\begin{array}{l}\text { A pharmacy technician was present in the ICU to help nurses withdraw drugs from } \\
\text { their care unit drug stocks }\end{array}$ & $1(2)$ & $0(0)$ & $1(13)$ \\
\hline No specific support activities were proposed & $7(17)$ & $7(21)$ & $0(0)$ \\
\hline $\begin{array}{l}\text { A pharmacy technician was present in other care units treating COVID-19 patients } \\
\text { to help nurses prepare drugs }\end{array}$ & $1(2)$ & $1(3)$ & $0(0)$ \\
\hline $\begin{array}{l}\text { A pharmacy technician was present in the ICU to help nurses prepare drugs (e.g. } \\
\text { preparation of injectables) }\end{array}$ & $0(0)$ & $0(0)$ & $0(0)$ \\
\hline
\end{tabular}

* Among 41 answers $\$$ Among 33 answers (German/Romansh) §Among 8 answers (French/Italian)

In general, clinical pharmacy services also provided tables with product characteristics and monitored every prescription closely (checking for interactions, contraindications, and correct dosage). 
medRxiv preprint doi: https://doi.org/10.1101/2020.12.08.20237339; this version posted December 11, 2020. The copyright holder for this

\section{OTHER ACTIVITIES AND PROBLEMS REPORTED IN WARDS}

$20 \%$ of HPs $(\mathrm{n}=8)$ implemented other support activities, e.g. a pharmacist and a pharmacy technician were present on weekends to support medical staff (stand-by service at the ICU). They were also in close communication with the ICU head. Pharmacy technicians took over some ICU administrative work or the centralised preparation of prefilled syringes for syringe pumps. Syringes (ketamine, noradrenaline, etc.) for ICUs were produced in HPs instead of by nurses. Medication reviews for patient treatments were also carried out. One head hospital pharmacist sat on an interdisciplinary physicians' committee (emergency, ICU, COVID ward, pneumology, cardiology and infectious diseases).

Regarding problems involving the administration of drugs used mainly in ICUs, $12 \%$ of HPs $(\mathrm{n}=5)$ experienced a lack of syringe pumps $(25 \% \mathrm{~F} / \mathrm{I}$ regions, $9 \% \mathrm{G} / \mathrm{R}$ regions) and $10 \%(\mathrm{n}=4)$ experienced a lack of injectable drugs ( $13 \%$ F/I regions, $9 \%$ G/R regions). $10 \%$ of HPs $(n=4)$ thought that care teams lacked experience in dealing with these drugs (13\% F/I regions, $9 \%$ $\mathrm{G} / \mathrm{R}$ regions). Among the HPs which faced problems involving the administration of drugs used mainly in ICUs, $60 \%(\mathrm{n}=9)$ designed alternative drug administration protocols to save on the number of syringe pumps or injectable formulations used, 33\% ( $n=5)$ managed the distribution and allocation of drug administration material, and $7 \%(n=1)$ developed protocols for remdesivir administration.

\section{HYGIENE AND PROTECTION}

$77 \%(\mathrm{n}=30)$ of HPs experienced problems procuring hand sanitiser solutions. The most significant problems were obtaining empty bottles $(n=14,47 \%)$ and basic ingredients $(n=11$, $37 \%)$, as well as dealing with over-consumption $(\mathrm{n}=10,33 \%)$. To solve these issues, 53\% $(n=16)$ of HPs manufactured solution or reconditioned bottles themselves; $50 \% \quad(n=15)$ received donations from outside their institution; $47 \%(n=14)$ outsourced this work to external companies and $10 \%(\mathrm{n}=3)$ imported solution. The Swiss civil protection corps and other volunteers helped to fill bottles.

Only $25 \%$ of HPs were involved $(15 \%, \mathrm{n}=6$ fully, and $10 \%, \mathrm{n}=4$ partly) in the management and distribution of protective masks. $70 \%$ of HPs $(n=7)$ provided information to healthcare professionals, $50 \%(\mathrm{n}=5)$ distributed materials from federal or cantonal stocks (drugs, personal protective equipment [PPE] and hand sanitiser solutions) at the cantonal or regional level, and 30\% ( $n=3)$ bought and distributed private stocks. Regarding surface disinfectants, $17 \%$ of HPs $(n=7)$ were consulted for their expert opinion and prepared documentation with guidelines on selected disinfectants; $15 \%(n=6)$ manufactured them.

\section{LIMITATIONS}

The present survey had some limitations. The first is that only $66 \%$ head hospital pharmacists who received the questionnaire answered it. Pharmacists who were not affiliated to the GSASA were not requested to participate because, as they generally do not work in acute care hospitals (but rather in psychiatric clinics or small private hospitals), they were potentially 
less affected by the imperatives of COVID-19 crisis management. Also, some participants failed to complete the whole survey, making comparisons between some answers difficult in a few cases.

\section{DISCUSSION}

Most head hospital pharmacists answered our survey, with a repartition in the different regions of Switzerland corresponding relatively to the speaking parts of Switzerland. The answering HPs corresponded meanly to organisations of 50 employees that mainly supplied hospitals with fewer than 300 beds (60\%), from 300 to 1000 beds (35\%) or more than 1000 beds (5\%). This distribution was representative of Switzerland's acute care hospitals, where 90\% ( $\mathrm{n}=252)$ have fewer than 300 beds, 10\% ( $\mathrm{n}=27)$ have from 300 to 1000 beds, and $1 \%$ $(n=2)$ has more than 1000 beds (9). During the first wave of the COVID-19 outbreak, most hospitals around the world increased their number of available beds (10,11). In Switzerland, for example, Lausanne University Hospital's Department of Internal Medicine increased its bed capacity by $65 \%$ (from 160 normally to 263 at the outbreak's peak) to ensure secure patient overflow (12). Increased bed availability was also reported in lots of countries, such as, for instance, the USA (13).

In some countries (14), HPs reorganised their activities to limit their HR risks: roles were redistributed and non-pharmacist staff were used to assist in manufacturing units and answer the phone (15). Another study reported HPs encouraging work from home and physical distancing (16). Our survey found that $47 \%(n=20)$ of HPs moved at-risk employees to safer environments. Personal fears regarding contamination risk originating in nursing homes or between colleagues was an issue in some HPs and should be considered in any future pandemic preparedness plans. Regarding psychological support for their teams, pharmacy heads should listen to staff's concerns and take proactive steps to identify and offer help and guidance to those at risk of burnout or experiencing psychological distress (16). To this end, $40 \%$ of HPs introduced team briefings and debriefings, and hierarchies calmed and reassured their staff. Indeed, Switzerland's Federal Office of Public Health has a pandemic preparedness plan (PPP) recommending that every organisation has a business continuity plan (17). During crisis management, in general, the presence of a team leader is crucial $(18,19)$. The PPP recommends that organisations create a "pandemic team" to manage their response to an outbreak. However, only $19 \%$ of the participating HPs set up a dedicated pandemic response team (44\% F/I regions, $12 \% \mathrm{G} / \mathrm{R}$ regions). Those teams were composed mainly of the head pharmacist and a representative of the pharmaceutical logistics unit (namely a pharmacist in charge of the logistics at HP). Among HPs with a disaster management plan, $52 \%$ created paper/electronic dashboards or other management tools (i.e. an Excel ${ }^{\circledR}$ file) especially for the COVID-19 crisis. In contrast, fewer HPs (36\%) had prepared an HR continuity plan. For $18 \%(n=7)$ a plan existed before the pandemic occurred and for the remaining $18 \%(\mathrm{n}=7)$, the plan was specially created to manage the pandemic: only $26 \%$ of German-speaking HPs, but $76 \%$ of French-speaking HPs. As numbers of contaminations grew during the crisis, $38 \%$ of French-speaking HPs created specific HR continuity plans, although 
only $13 \%$ of the German-speaking HPs did. This reflected the fact that French-speaking regions suffered more contaminations than German-speaking regions, which thus felt less need to create those plans (20).

Clinical and hospital pharmacists promoted also safe, effective medication management among COVID-19 patients and participated in guideline development in partnership with care providers (physicians, infectiologists and other specialists) and pandemic management experts. A scoping review of pharmacists' roles during the pandemic suggested that HPs provided drug information to healthcare professionals as part of their daily activities (21). The 11 relevant studies examined identified the services provided by hospital pharmacists in the USA, China, Saudi Arabia, Taiwan and Macao. This significant review, conducted by the Federal Rural University of Rio de Janeiro's Department of Pharmaceutical Sciences, was the first to highlight that counselling healthcare professionals and patients on drugs were the main action carried out by hospital pharmacists during the pandemic. Indeed, the COVID-19 outbreak revealed new opportunities for hospital pharmacists as they stepped into new roles (greater involvement in thinking about treatment choices, counselling about drugs saving strategy), suggesting that fully integrated, inter-sectoral, inter-professional collaboration is necessary to face crises and public health emergencies effectively (22).

Moreover, our survey found that $20 \%$ of HPs put a pharmacist in ICUs to support nurses, and $24 \%$ of HPs put a pharmacist there to support physicians. Specific COVID-19 documents were drawn up to respond to medical needs with regards to drug administration (29\% of HPs), drug preparation (29\% of HPs), and treatment choices (24\% of HPs). Higher incidences of stockouts were to be expected during a pandemic; thus, drug stocks in care units treating COVID-19 patients were managed by either increasing existing stocks (54\% of HPs) or creating extra storage space (51\% of HPs). Drug management in wards treating COVID-19 patients generated some adjustments to routine roles. Some HPs assigned a pharmacist team to daily medication stock controls in care units treating COVID-19 patients. Other HPs assigned pharmacy technicians to manage stocks on wards.

At the central pharmacy, to limit the risks of shortages, reserve supplies had been planned for in $56 \%$ of HPs (100\% F/I regions, $45 \% \mathrm{G} / \mathrm{R}$ regions). At the beginning of the pandemic, it was very difficult for HPs to anticipate which drugs would be used the most and thus which had to be ordered, bought and stocked in sufficient quantities. This raises the question of risk perception, which seems to have been different in French- and German-speaking regions regarding the number of COVID-19 patients expected. It is noteworthy that $22 \%$ of HPs experienced no stockouts at all (13\% F/I regions, $24 \%$ G/R regions). French-speaking regions made more preventive stocks, but also experienced relatively more stockouts. Once again , this might be explained by the fact that French-speaking regions were more affected by the pandemic.

\section{CONCLUSIONS}


This was the first national-level study on the interventions undertaken by hospital pharmacies (HPs) in acute care hospitals across Switzerland in response to the vast new challenges encountered during the COVID-19 pandemic. The findings illustrated the wide range of activities undertaken by HPs with regards to crisis management, but they identified major areas of concern that emerged due to this public health crisis. The lessons and experiences outlined here could be used to prepare for similar future events in Switzerland such as in any HP in Europe or in other parts of the world.

Future improvements in crisis response will require action at many levels: in HPs, hospitals, cantons and nationally. To prevent stockouts, the manufacture of drugs and medical devices within Switzerland should be promoted. Generally, for subsequent waves of the pandemic in Switzerland, the following measures are recommended to hospital pharmacists: 1) update SOPs and emergency planning procedures; 2) develop worst-case scenario plans for dealing with supply chain and train them; 3) refine business continuity plans; 4) maintain dashboards and concepts used in the first wave (e.g. communication concept); 5) ensure that protection measures and hygiene and social distancing rules are respected; 6) anticipate and ensure minimal pharmacy stock needs by stocking "pandemic inventories" of drugs, disinfectants and PPE; 7) monitor and evaluate drug use, availability and shortages; 8) exchange directly with stakeholders (wards, public administration, etc.).

\section{KEY MESSAGES}

\section{WHAT WAS ALREADY KNOWN ON THIS SUBJECT:}

Switzerland has a pandemic preparedness plan recommending that every organisation has its own business continuity plan.

- The COVID-19 pandemic first wave represented a vast challenge to hospital pharmacists with various surprises.

\section{WHAT THIS STUDY ADDS:}

- The COVID-19 pandemic generated unprecedented global demand for specific drugs, hand sanitiser solution, and other therapeutic products, particularly in critical care settings, highlighting the essential role of hospital pharmacists in such crises.

Key COVID-19 responses at the hospital pharmacy level included staff flexibility with regards to changes in roles and procedures, communication, teamwork and solidarity, and the need to prepare business continuity plans and management dashboards

Managing and facing complex pandemic response reveals the importance of involving hospital pharmacists in pandemic response steering committees at many levels. The lived experiences during the pandemic must be reviewed and evaluated to raise awareness and guide future policy responses for when the next crisis occurs. 
medRxiv preprint doi: https://doi.org/10.1101/2020.12.08.20237339; this version posted December 11, 2020. The copyright holder for this preprint (which was not certified by peer review) is the author/funder, who has granted medRxiv a license to display the preprint in perpetuity.

\section{CONTRIBUTIONS TO THE ARTICLE}

LS: Conceptualization, Data curation, Formal analysis, Investigation, Methodology, Writing original draft

YD: Conceptualization, Data curation, Formal analysis, Investigation, Methodology, Writing - original draft

PB: Conceptualization, Funding acquisition, Methodology, Supervision, Writing - review \& editing

NW: Conceptualization, Funding acquisition, Methodology, Supervision, Writing - review \& editing

\section{REFERENCES}

1. Liu DX, Liang JQ, Fung TS. Human Coronavirus-229E, -OC43, -NL63, and -HKU1. Ref Module Life Sciences 2020; 2020: B978-0-12-809633-8.21501-X.

2. Zhu Z, Lian X, Su X et al. From SARS and MERS to COVID-19: a brief summary and comparison of severe acute respiratory infections caused by three highly pathogenic human coronaviruses. Respir Res 2020;21(1):224.

3. Han Q, Lin Q, Jin S et al. Coronavirus 2019-nCoV: A brief perspective from the front line. J Infect 2020;80(4):373 $\square 7$.

4. World Health Organisation (WHO). World Health Organisation Website: COVID-19 [Internet]. [cited 30 sept 2020]. Available at:

https://www.who.int/fr/emergencies/diseases/novel-coronavirus-2019/technicalguidance/naming-the-coronavirus-disease-(covid-2019)-and-the-virus-that-causes-it.

5. Remuzzi A, Remuzzi G. COVID-19 and Italy: what next? Lancet 2020;395(10231):1225 $\square$.

6. Schumacher L, Blatrie C, Krähenbühl S, et al. Gestion de la pandémie COVID-19 en Suisse: Rôles et défis d'une pharmacie interhospitalière. Méd Catastrophe Urg Collectives 2020;4(3):223-32.

7. Droz R. Opération CORONA 20. Rev Mil Suisse 2020;4:5-7.

8. Swiss Federal Office of Public Health (FOPH). COVID-19. Situation Suisse: Répartition par canton, âge et sexe. [cited 30 sept 2020]. Available at: https://covid- 19schweiz.bagapps.ch/fr-1.html.

9. Swiss Federal Office of Public Health (FOPH). Chiffres clés des hôpitaux suisses 2018. [cited 25 sept 2020]. Available at: https://www.bag.admin.ch/bag/fr/home/zahlen-undstatistiken/zahlen-fakten-zu-spitaelern/kennzahlen-der-schweizer-spitaeler.html.

10. Société Suisse de Médecine Intensive. COVID-19: Occupation précédente des unités de soins intensifs suisses et le rôle de la médecine intensive face à une nouvelle 
augmentation des taux d'infection. Available at: https://www.sgi-ssmi.ch/fr/newsdetail/items/522.html.

11. Carballo S, Agoritsas T, Darbellay P et al. COVID-19: Réorganisation sous toutes ses formes dans un hôpital universitaire. Forum Médical Suisse 2020;20(2730):390-395.

12. Garnier A, Vaucher J, Bianchi C et al. Organizational Impacts and Clinical Challenges of the COVID-19 Pandemic on a Swiss Tertiary Internal Medicine Department. Rev Med Suisse 2020;16(N 691-2):869-874.

13. Sin JH, Richards II, Ribisi MS. Maintaining comprehensive pharmacy services during a pandemic: recommendations from a designated COVID-19 facility. Am J Health-Syst Pharm 2020;77(18):1522-1528.

14. Adam J-P, Khazaka M, Charikhi F, et al. Management of human resources of a pharmacy department during the COVID-19 pandemic: take-aways from the first wave. Res Soc Adm Pharm 2020;S1551-7411(20)31147-5.

15. Zuckerman AD, Patel PC, Sullivan M et al. From natural disaster to pandemic: A healthsystem pharmacy rises to the challenge. Am J Health Syst Pharm 2020;77(23):1986-1993.

16. Siddiqui MA, Abdeldayem A, Abdel Dayem K et al. Pharmacy leadership during emergency preparedness: Insights from the Middle East and South Asia. Am J HealthSyst Pharm 2020;77(15):1191 $\square$.

17. Swiss Federal Office of Public Health (FOPH). Plan de pandémie, Manuel pour la préparation des entreprises. 3rd ed. 2019.

18. Carresi AL. The 2004 Madrid train bombings: an analysis of pre-hospital management. Disasters 2008;32(1):41 $\square 65$.

19. Carron P, Dami F, Frei O et al. Médecine d'urgence préhospitalière. 1st ed. 2013.

20. Swiss Federal Office of Public Health (FOPH). Maladie à coronavirus 2019 (COVID-19): Rapport sur la situation épidémiologique en Suisse et dans la Principauté de Liechtenstein - semaine 25 (15 au 21.6.2020). Bern, Switzerland 2020.

21. Visacri MB, Figueiredo IV, Lima T de M. Role of pharmacist during the COVID-19 pandemic: a scoping review. Res Social Admin Pharm 2020 Epub. doi:10.1016/j.sapharm.2020.07.003.

22. Bragazzi NL, Mansour M, Bonsignore A et al. The Role of Hospital and Community Pharmacists in the Management of COVID-19: Towards an Expanded Definition of the Roles, Responsibilities, and Duties of the Pharmacist. Pharmacy. 2020;8(3)140. 